\title{
New genus and three new species of quill mites (Acari: Syringophilidae: Picobiinae) parasitising puffbirds (Aves: Piciformes)
}

\author{
Maciej Skoracki, Katarzyna Scibek and Bozena Sikora
}

Department of Animal Morphology, Faculty of Biology, Adam Mickiewicz University, Umultowska 89, 61-614 Poznan, Poland

\begin{abstract}
Three new species, belonging to the newly proposed genus Pseudopicobia gen. n., inhabiting body quill feathers of puffbirds (Piciformes: Bucconidae), are described: P. nonnula sp. n. from Nonnula frontalis (Sclater) in Colombia, P. malacoptila sp. $\mathrm{n}$. from Malacoptila panamensis Lafresnaye in Colombia and P. hapaloptila sp. n. from Hapaloptila castanea (Verreaux) in Ecuador. The new genus differs from morphologically similar genus Picobia Heller, 1878 by the absence of the genital setae, absence of the genital lobes, solenidia $\varphi \mathrm{I}$ represented by microsetae, and by the presence of setiform solenidia $\sigma \mathrm{I}$. Syringophilid mites are recorded from birds of this family for the first time.
\end{abstract}

Keywords: Acari, Pseudopicobia, new genus, ectoparasites, birds, Bucconidae

The quill mites of the family Syringophilidae (Acari: Prostigmata: Cheyletoidea) are diverse group of permanent and highly specialized ectoparasites of birds inhabiting the feather quills. They live and reproduce inside the flight and body feathers feeding on the soft tissue fluids of their hosts by piercing the calamus wall with their long and flexible chelicerae (Kethley 1971). Transmission of these mites is mainly vertical, from parents to their offspring, but occasionally horizontal transfer, from one adult host to another, is also possible (Nattress 2011). Although we have little data on the pathogenicity of these mites and their negative impact on condition of birds, some authors suggest that they may play a role as potential enzootic vectors for pathogens (Skoracki et al. 2006).

Syringophilids are mono- or oligoxenous parasites associated with birds of different orders throughout the world. To date this family includes more than 269 species in 53 genera recorded from more than 180 bird species belonging to 69 families of 21 orders (Skoracki and O’Connor 2010, Skoracki 2011, Skoracki et al. 2011, 2012).

The subfamily Picobiinae Johnson et Kethley, 1975 is a taxonomically diverse group as it was estimated based on the number of their potential host species (Johnston and Kethley 1973). To date, it comprises only 35 species grouped in five genera. Members of this subfamily inhabit a wide spectrum of avian hosts. The monotypic genus Calamincola Casto, 1977 is known from cuculiform birds. Five species of Columbiphilus Kivganov et Sharafat, 1995 were collected from birds of the orders Columbiformes, Galliformes, and Pteroclidiformes. The most diverse genus Picobia Haller, 1878 includes 19 species found on Passeriformes, Piciformes, and Upupiformes. Ten species of the genus Neopicobia Skoracki, 2011 are associated with bird orders Passeriformes, Psittaciformes, Piciformes, and Columbiformes (Casto 1977, Kivganov and Sharafat 1995, Skoracki 2011). The monotypic genus Rafapicobia Skoracki, 2011 is known only from passerines. All members of the subfamily Picobiinae occupy exclusively body feathers, except enigmatic species Calamincola lobatus Casto, 1977 collected from various flight feathers of Crotophaga sulcirostris Swainson (Casto 1977).

In the current study we propose a new genus of syringophilid mites to accommodate three new species that were collected from quill feathers of birds belonging to the family Bucconidae (Aves: Piciformes).

\section{MATERIALS AND METHODS}

Specimen collection and preparation. The mite materials used in the present study were collected in the ornithological collection of the Bavarian State Collection of Zoology, Munich, Germany (ZSM) from dry bird skins. Before mounting, mites were softened and cleared in Nessbitt Solution at $60^{\circ} \mathrm{C}$ for 1-2 hours. For light microscope study mites were mounted on slides in Faure medium and investigated under the light microscope Olympus BH-2 with differential interference contrast (DIC) illumination. Drawings were made using a drawing attachment. All measurements are given in micrometres. Measurements (ranges) of paratypes are given in brackets following data of holotype.

Terminology. The idiosomal setation follows Grandjean (1939) as adapted for Prostigmata by Kethley (1990). Nomen- 
clature of leg chaetotaxy follows that proposed by Grandjean (1944). The application of these chaetotactic schemes to Syringophilidae was recently provided by Bochkov et al. (2008). Morphological terminology follows Skoracki (2011). The scientific names of the birds follow Clements (2007).

Abbreviations. Specimen depositories and reference numbers are cited using the following abbreviations: AMU - A. Mickiewicz University, Department of Animal Morphology, Poznan, Poland; IPCAS - Institute of Parasitology, Biology Centre of the Academy of Sciences of the Czech Republic, České Budějovice, Czech Republic; ZSM - Bavarian State Collection of Zoology, Munich, Germany; ZISP - Zoological Institute of the Russian Academy of Sciences, St. Petersburg, Russia.

\section{RESULTS}

Family: Syringophilidae Lavoipierre, 1953

Subfamily: Picobiinae Johnston et Kethley, 1973

Genus: Pseudopicobia gen. n.

Type species: Pseudopicobia nonnula sp. n.

\section{Diagnosis}

Female. Medium to large-sized syringophilids (total body length 485-845). Gnathosoma: Hypostomal apex rounded. Lateral hypostomal teeth absent. Peritremes M-shaped, with clearly visible chambers in each branch. Movable cheliceral digits edentate. Stylophore rounded posteriorly. Idiosoma: Dorsal propodonotal setae beaded. Six pairs of propodonotal setae present, arranged 2-1-1-2. Propodonotal shield divided longitudinally, forming two narrow shields bearing bases of setae ve, si and se; unpaired shield between these shields absent. Hysteronotal shield absent. Hysteronotal setae long. Setae $d 1$ situated closer to $e 2$ than to $d 2$ or located equidistant between $d 2$ and $e 2$. Pygidial shield present or absent. Terminal setae $f 1, f 2$ short, setae $h 2$ long. Bases of setae $1 a-1 a$ coalesced, $3 a-3 a$ not coalesced. Pseudanal series represented by two pairs of setae. Genital setae absent. Aggenital series with three pairs of setae. Aggenital plate absent. Genital plate present. Genital lobes absent. Legs: Legs I and II thicker than III and IV. Apodemes I parallel with thorn-like protuberances in middle part. Legs with full complement of solenidia, solenidia $\varphi$ I represented by microsetae, solenidia $\sigma \mathrm{I}$ setiform. Antaxial and paraxial members of claw pair of legs III and IV unequal in size and shape.

Male. Features as in females except: small-sized mites (total body length 300); hypostomal apex rounded; propodonotal setae arranged 2-1-1-2; hysteronotal shield present, not fused to pygidial shield; hysteronotal setae $d 2$ long; setae $d 1$ and $e 2$ short; pseudanal series represented by two pairs of setae; genital series with two pairs of setae; aggenital series with two pairs of setae.

Ety mology: The name of the new genus reflects its resemblance to the genus Picobia.

Differential diagnosis. This new genus is morphologically similar to Picobia. In both genera females have clearly visible chambers in each branch of the peritremes; the propodonotal shield is divided longitudinally, forming two narrow shields bearing bases of setae ve, si and $s e$; the hysteronotal shield is absent; setae $1 a-1 a$ are coalesced; the apodemes I are parallel and with thorn-like protuberances in middle part; the legs have a full complement of solenidia. Females of this new genus differ from females of Picobia by the following characters: in females of Pseudopicobia gen. n., genital setae are absent; genital lobes are absent; differentiation between physogastric form and non-physogastric form is difficult; solenidia $\varphi \mathrm{I}$ are represented by microsetae, solenidia $\sigma \mathrm{I}$ are setiform. In females of Picobia, a pair of genital setae is present, genital lobes are present, physogastric forms are vermiform in outline and are about 2-3 longer than non-physogastric form; solenidia $\varphi \mathrm{I}$ are not reduced to minute structures, solenidia $\sigma \mathrm{I}$ are bulb-like.

Habitat, host range and distribution. Mites of this genus inhabit quills of body feathers and are associated with puffbirds (Piciformes: Bucconidae) in the Neotropical region.

\section{Pseudopicobia nonnula sp. n.}

Figs. 1-13

Female, holotype. Total body length 700 (605-680 in four paratypes). Gnathosoma: Infracapitulum sparsely punctate. Movable cheliceral digit 115 (115) long. Each medial branch of peritremes with 3-4 chambers, each lateral branch with 5-6 chambers. Stylophore 160 (155165) long. Idiosoma: Two narrow propodonotal shields sparsely punctate near bases of setae si. Length ratio of setae $v i$ : ve : si $1: 1.1-1.3: 1.2-1.4$. Bases of setae $v i$ situated posterior to level of setae ve. Setae $v i$, ve and si lightly beaded, other idiosomal setae smooth. Setae se situated posterior to level of setae $\mathrm{c} 1$. Hysteronotal shield absent. Setae $d 2$ slightly (1.1-1.2 times) longer than $d 1$ and $e 2$. Pygidial shield present. Setae $f 21.6-1.8$ times longer than f1. Setae $h 1$ 2-3.5 times longer than f1. Aggenital setae agl situated anterior to level of setae ag2. Length ratio of setae $a g 1: a g 2: a g 3$ 1.9-2: $1: 2.2$. Genital plate present. Both pairs of pseudanal setae subequal in length or setae $p s 2$ slightly longer than $p s 1$. All coxal fields well sclerotized, I densely punctate, II sparsely punctate, III and IV apunctate. Setae $3 c$ about twice as long as 3b. Legs: Setae l'RIII reach to tarsus. Setae $t c$ ' and $t c$ "' of legs III and IV subequal in length. Lengths of setae: vi 130 (100-115), ve (120-130), si 155 (120 145), se 200 (180-195), c1 220 (180-205), c2 (150-160), d1 140 (150-155), d2 170 (160-165), e2 130 (125-140), fl 50 (50-55), f2 80 (80-90), h1 140 (110-170), h2 (335), ag1 130 (125), ag2 65 (65), ag3 140 (140-145), ps1 20 (20), ps2 (20-30), tc 'III-IV and tc'III-IV (50-60), l'RIII 60 (60-70), l'RIV (45), $3 b 50$ (45-50), 3c 100 (90-100).

Male. Total body length 300 in one paratype. Gnathosoma: Infracapitulum apunctate. Each medial branch of peritremes with 3-4 chambers, each lateral branch with six chambers. Stylophore 80 long. Idiosoma: Propodono- 

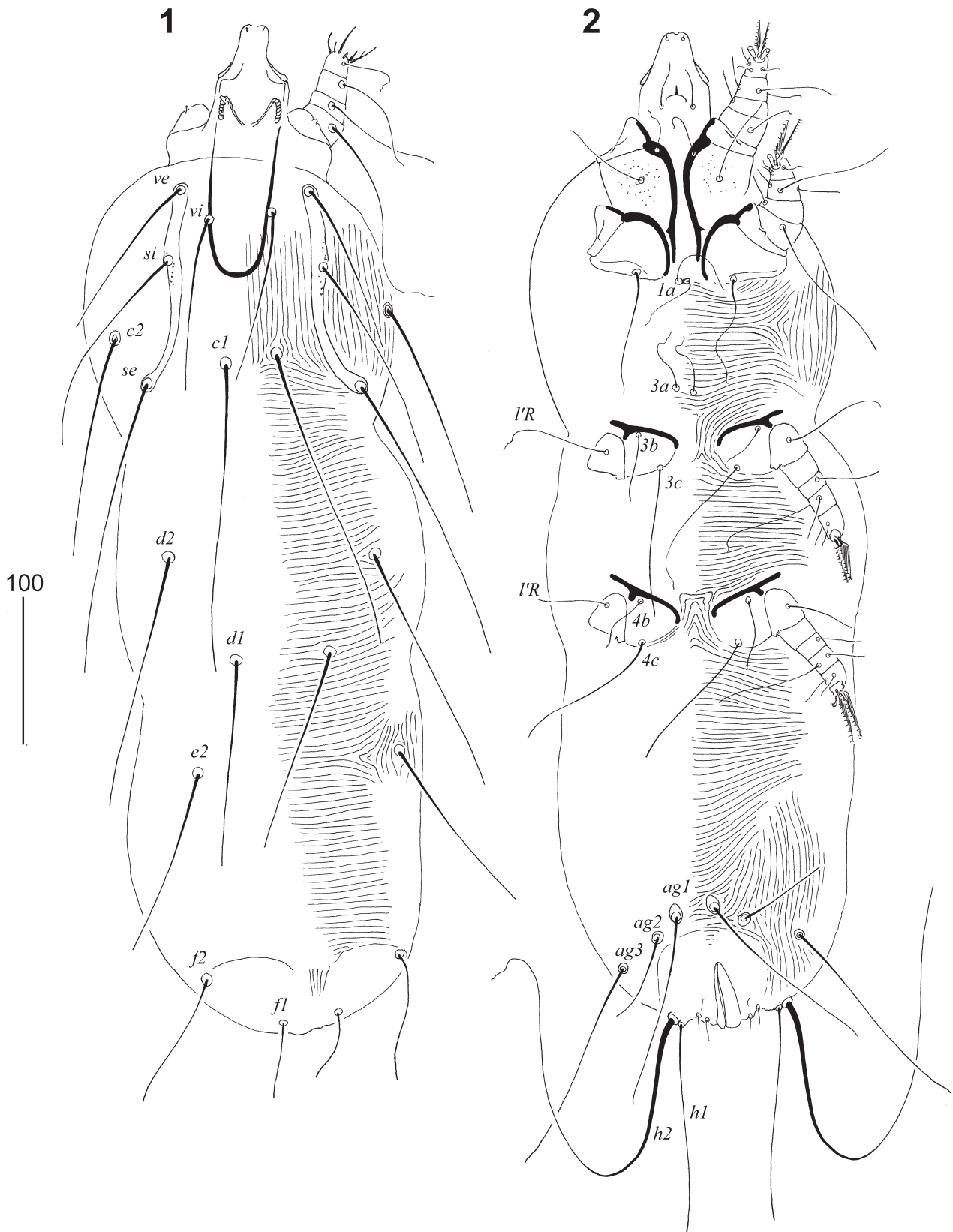

Figs. 1, 2. Pseudopicobia nonnula sp. n., female. $\mathbf{1}$ - dorsal view; $\mathbf{2}$ - ventral view.

tal shield divided into two lateral shields, densely punctate between bases of setae $v e$ and si. Length ratio of setae $v i$ : ve : si $1: 1.3: 1.8$. Bases of setae vi situated posterior to level of setae ve. Setae vi, ve and si lightly beaded, other idiosomal setae smooth. Setae se situated posterior to level of setae $\mathrm{c} 1$. Hysteronotal shield entire, apunctate, bearing bases of setae $d 1$ and $e 2$. Setae $d 25.5$ times longer than $d 1$ and $e 2$. Pygidial shield apunctate. Aggenital setae ag1 about twice as long as ag2. Aggenital plate absent. All coxal fields well sclerotized, I densely punctate, II sparsely punctate, III and IV apunctate. Lengths of setae: vi 40, ve 50, si 70, se 110, c1 110, c2 100, d1 10, d2 55, e2 10, f2 10, ag1 55, ag2 25.
Ty p e host: Grey-cheeked nunlet Nonnula frontalis (Sclater, 1854) (Piciformes, Bucconidae).

Locality: Colombia, Bogota $\left(4^{\circ} 35^{\prime} 53.00^{\prime \prime} \mathrm{N}, 7^{\circ} 04^{\prime} 33.00^{\prime \prime} \mathrm{W}\right)$, no other data. Host specimen deposited in the ZSM. Mites removed by M. Skoracki.

Site of infection: Quills of body feathers.

Type material: Female holotype, two female paratypes and one male paratype are deposited in the AMU (Reg. No. AMU-SYR.366), one female paratype in the ZSM (Reg. No. ZSM20112030), one female paratype in the IPCAS-2032.

E ty mology: The name of this new species refers to the generic name of the host - Nonnula.

Differential diagnosis: Pseudopicobia nonnula sp. $\mathrm{n}$. is morphologically similar to $P$. hapaloptila $\mathrm{sp}$. n. In fe- 

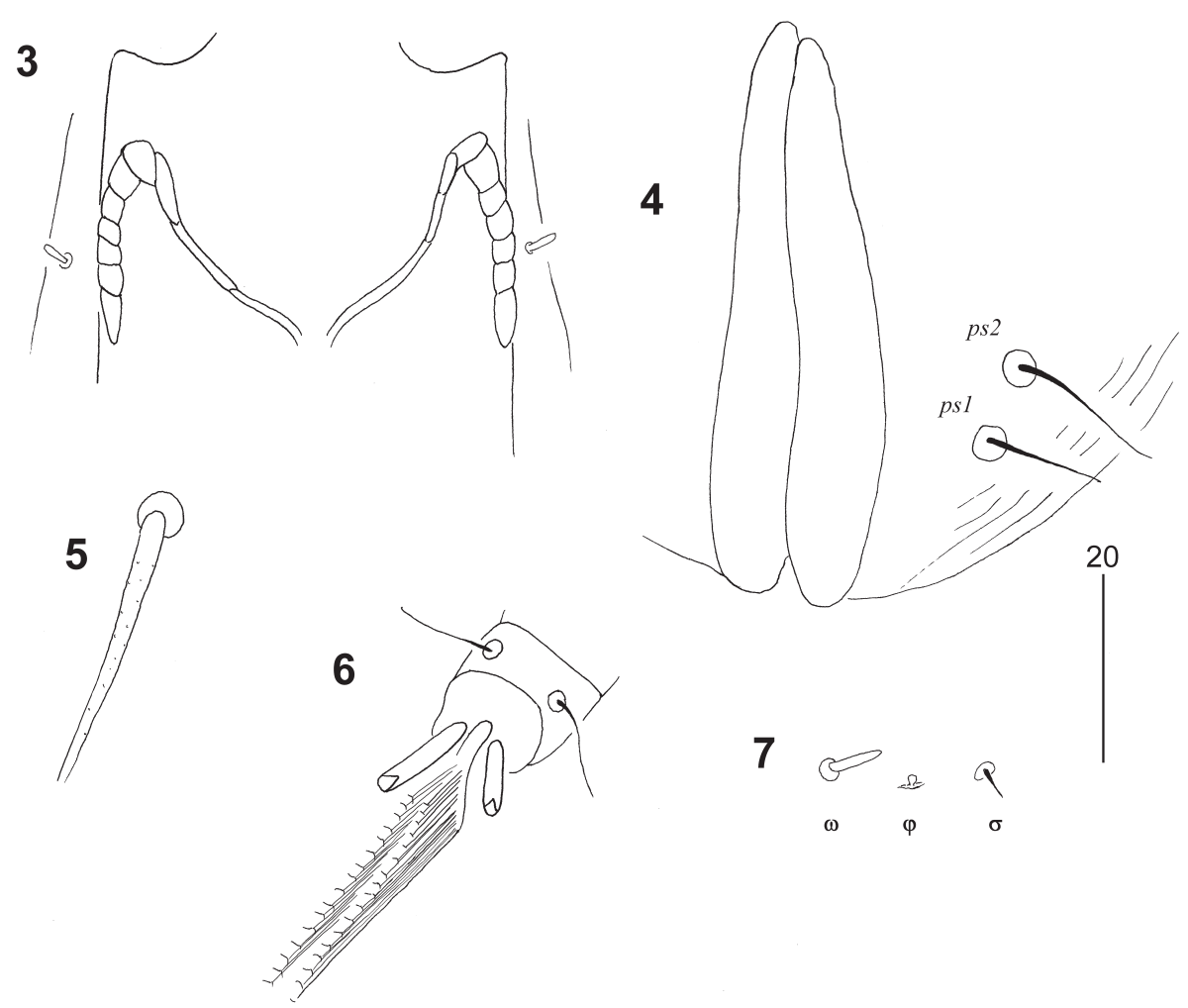

Figs. 3-7. Pseudopicobia nonnula sp. n., female. 3 - peritremes; 4 - genital region in ventral view; 5 - propodonotal seta ve; 6 - tarsus of leg III in ventral view; 7 - solenidia of leg I.

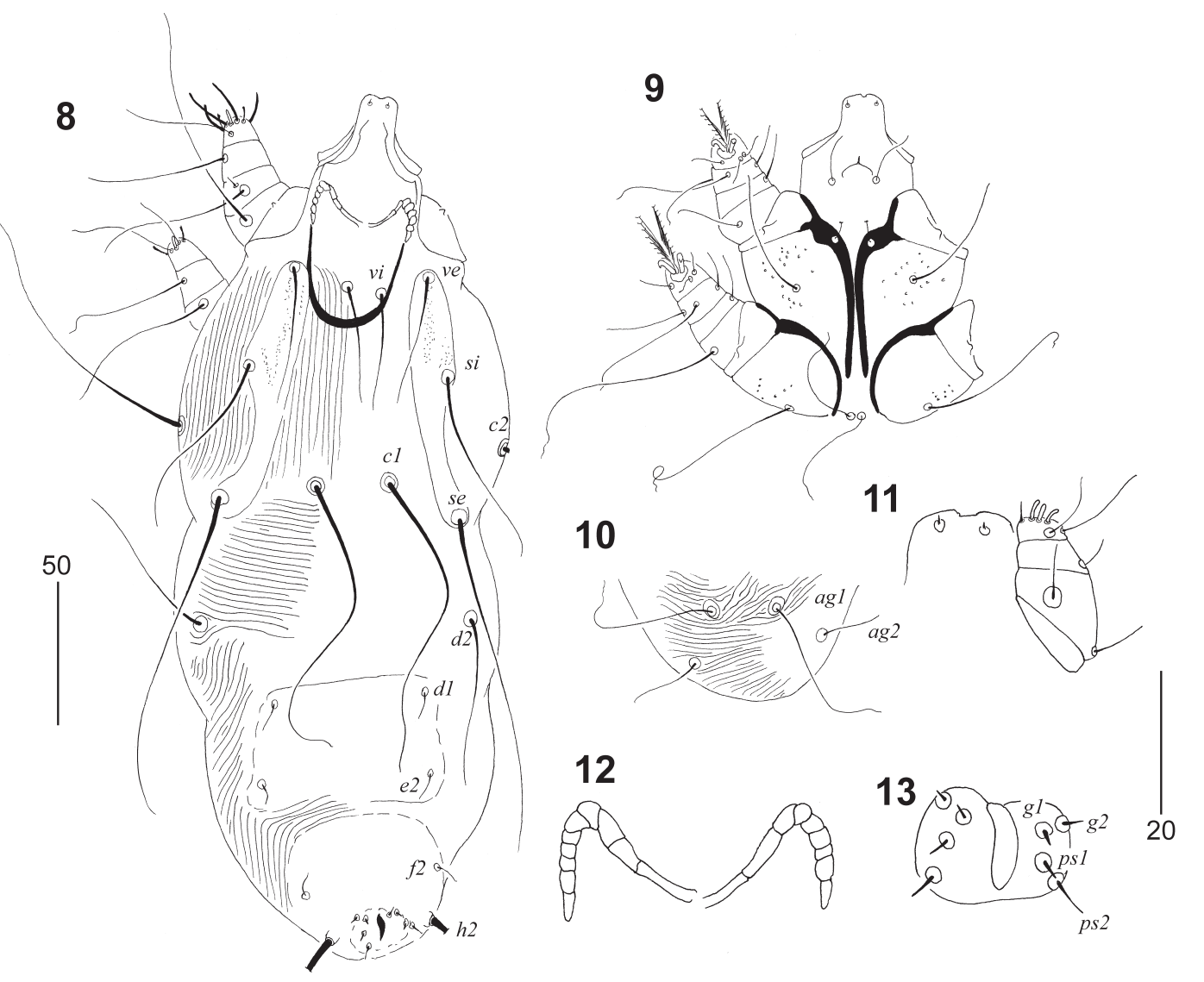

Figs. 8-13. Pseudopicobia nonnula sp. n., male. 8 - dorsal view; 9 - propodosoma in ventral view; 10 - opisthosoma in ventral view; $\mathbf{1 1}$ - gnathosoma in ventral view; 12 - peritremes; 13 - genito-anal region. 


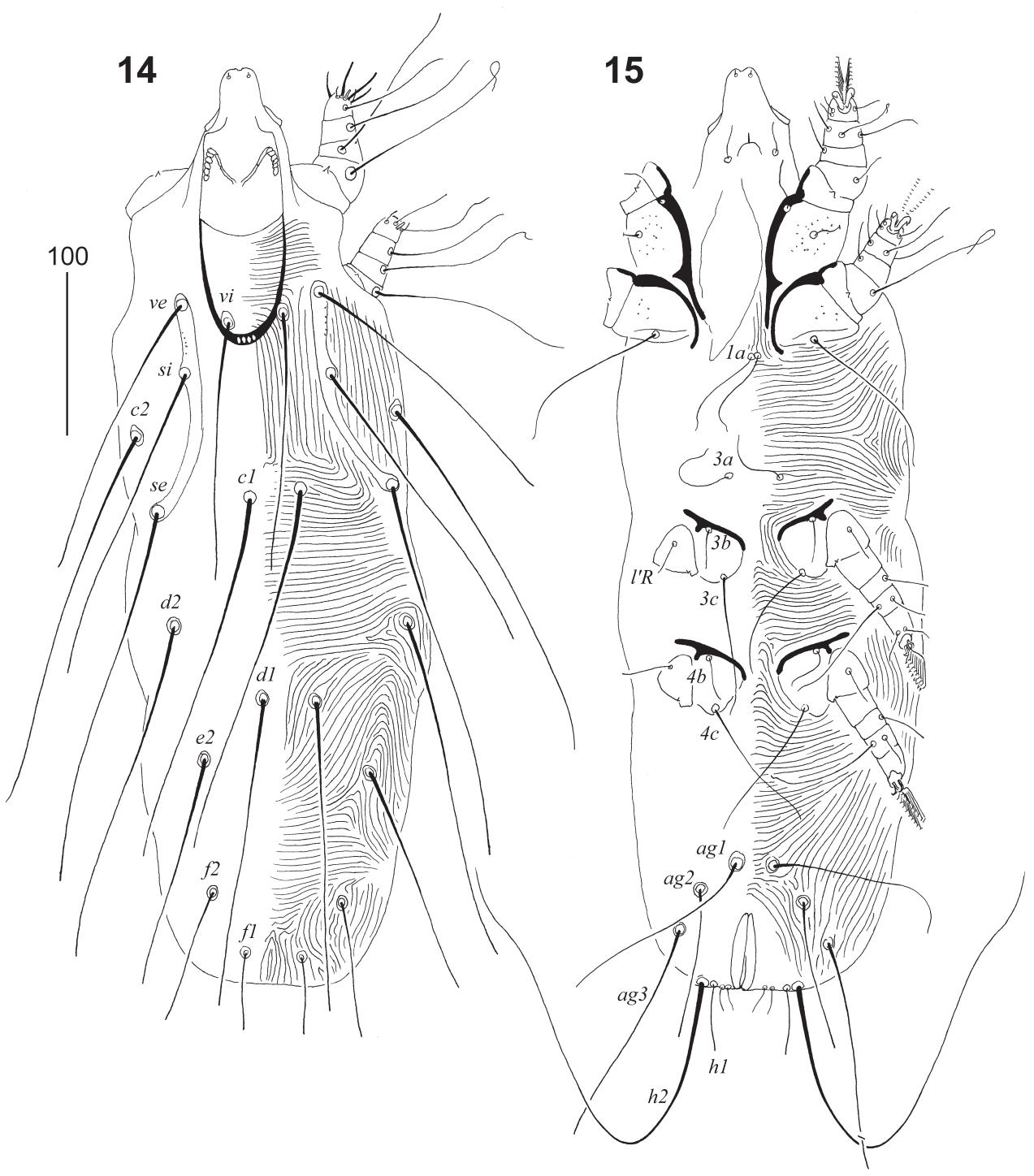

Figs. 14, 15. Pseudopicobia malacoptila sp. n., female. 14 - dorsal view; 15 - ventral view.

males of both species the pygidial shield is present and well sclerotised. This new species differs from $P$. hapaloptila by the following characters: in females of $P$. nonnula the length ratios of setae $v i$ : si and ag1 : ag2 are $1: 1.2-1.4$ and 1.9-2 : 1, respectively; leg setae l'RIII reach to the tarsus; setae $h 12.1$ times longer than ag2. In females of $P$. hapaloptila the length ratios of setae $v i: s i$ and $\operatorname{ag} 1:$ ag2 are $1: 1$ and $1.2-1.3: 1$, respectively; leg setae l'RIII reach, at most, to genu; setae $h 1$ and $a g 2$ are subequal in length.

\section{Pseudopicobia malacoptila sp. n.}

Figs. 14-23

Female, holotype. Total body length 570 (485-765 in six paratypes). Gnathosoma: Infracapitulum apunctate. Movable cheliceral digit 125 (120-125) long. Each medial branch of peritremes with three chambers, each lateral branch with seven chambers. Stylophore 170 (165-170) long. Idiosoma: Propodonotal shield divided into two nar- row and apunctate lateral shields. Length ratio of setae $v i$ : ve : si $1: 1.1-1.2: 1.3$. Bases of setae vi situated slightly posterior to level of setae ve. Setae vi, ve and si lightly beaded, other idiosomal setae smooth. Setae se and $c 1$ situated at same transverse level. Pygidial shields absent. Setae $d 1$ and $d 2$ subequal in length, both slightly longer (1.3 times) than $e 2$. Setae $f 2$ 1.4-1.9 times longer than fl. Setae $f 1$ 1.3-1.6 times longer than $h 1$. Aggenital setae agl situated anterior to level of setae ag2. Length ratio of setae ag1 : ag2 : ag3 1.3-1.7 : $1:$ 1.5-2. Genital plate present. Both pairs of pseudanal setae subequal in length. All coxal fields well sclerotized, I and II punctate, III and IV apunctate. Setae $3 c 3.5$ times longer than $3 b$. Legs: Setae $t c$ ' and $t c$ " of legs III and IV subequal in length. Lengths of setae: vi 160 (150-175), ve 180 (175-180), si (setae $s i$ are broken in the holotype) (200-215), se 235 (215-225), c1 235 (220-250), c2 240 (215-230), d1 195 (180-195), d2 220 (190-205), e2 145 (140-150), f1 45 


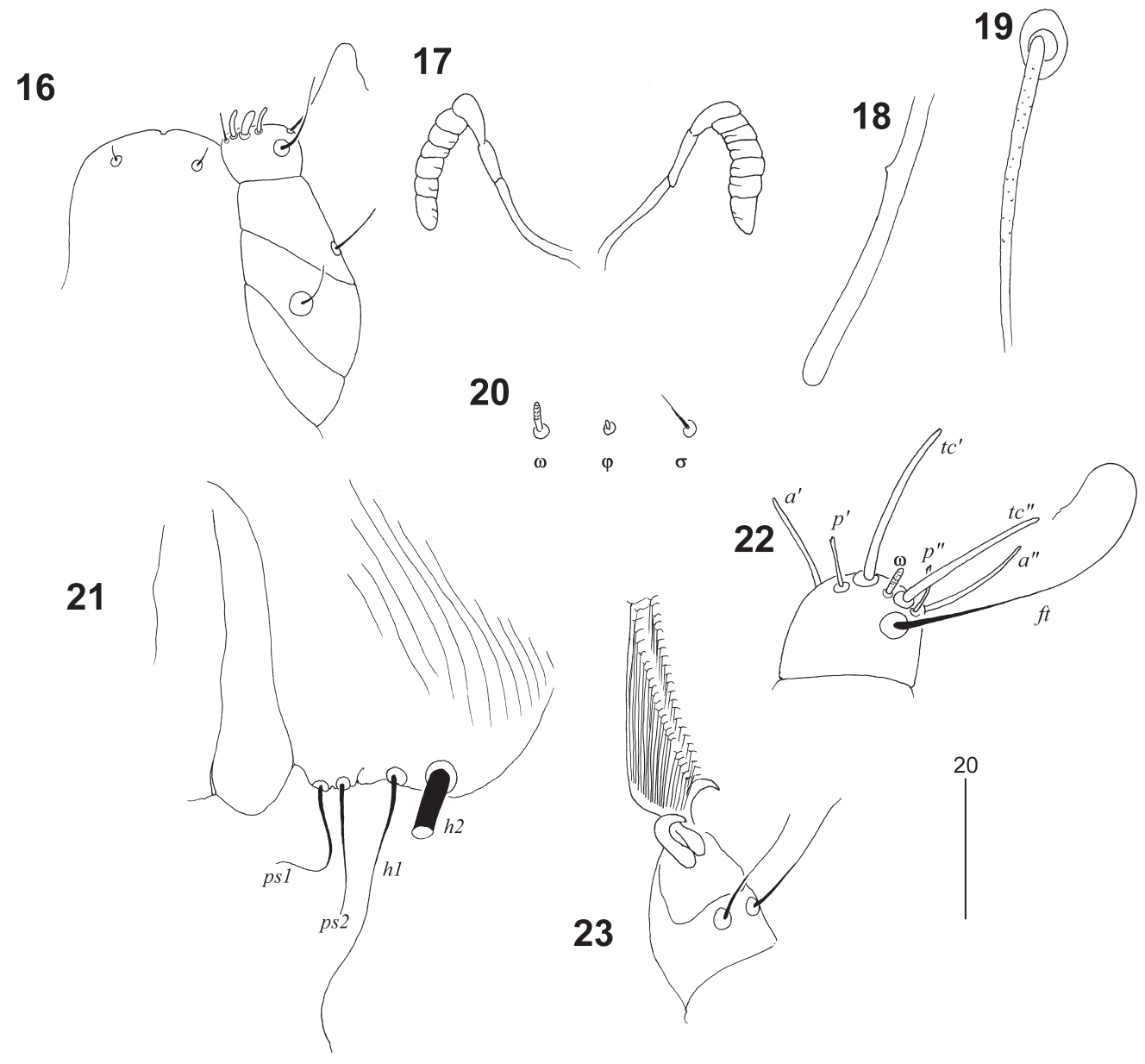

Figs. 16-23. Pseudopicobia malacoptila sp. n., female. 16 - gnathosoma in ventral view; 17 - peritremes; 18 - posterior part of movable cheliceral digit; 19 - propodonotal seta ve; 20 - solenidia of leg I; 21 - genital region in ventral view; 22 - tarsus of leg I in dorsal view; 23 - tarsus of leg III in ventral view.

(45-55), f2 $70(65-85), h 135$ (25-30), h2 (300-320), ag1 125 (120-140), ag2 95 (80-90), ag3 140 (145-165), ps 1 and ps2 (20), tc'III-IV 55 (55), tc' III-IV 60 (50-55), l'RIII 25 (25), l'RIV 25 (25), $3 b 25$ (25), 3c 90 (85-90).

Male. Not found.

Type host: White-whiskered puffbird Malacoptila panamensis Lafresnaye, 1847 (Piciformes: Bucconidae).

Locality: Colombia, Antioquia, Mutatá $\left(7^{\circ} 14^{\prime} 59.96 " \mathrm{~N}\right.$, $\left.76^{\circ} 25^{\prime} 59.68^{\prime \prime} \mathrm{W}\right), 08.08 .1966$, coll. J. Haffer. Host specimen deposited in the ZSM (Reg. No. 67.386). Mites removed by M. Skoracki.

Site of infection: Quills of body feathers.

Type material: Female holotype and five female paratypes are deposited in the AMU (Reg. No. AMU-SYR.364), one female paratype in the ZSM (Reg. No. ZSM20112029), one female paratype in the ZISP (Reg. No. ZISP AVB 0112908-029), and one female paratype in the IPCAS-2033.

Etymology: Named after the generic name of the host Malacoptila.
Differential diagnosis: Females of this new species are distinguished from other species of this genus by the absence of the pygidial shield.

\section{Pseudopicobia hapaloptila sp. n.}

Figs. 24-29

Female, holotype. Total body length 845. Gnathosoma: Infracapitulum sparsely apunctate. Movable cheliceral digit 120 (120 in two paratypes) long. Each medial branch of peritremes with 5-6 chambers, each lateral branch with seven chambers. Stylophore 170 (175) long. Idiosoma: Pair of narrow propodonotal shields apunctate. Length ratio of setae $v i$ : ve : si $1: 1: 1$. Bases of setae $v i$ situated posterior to level of setae ve. Setae $v i$, ve and si lightly beaded, other idiosomal setae smooth. Setae se situated posterior to level of setae $\mathrm{c} 1$. Hysteronotal shield absent. Setae $d 1, d 2$ and $e 2$ subequal in length. Pygidial shield present. Setae $h 1$ 1.4-1.8 times longer than $f 1$. Setae $f 2$ about twice as long as $f 1$. Aggenital setae ag 1 situated anterior to level of setae $a g 2$. Length ratio of setae ag1 : ag2 : ag3 1.2-1.3 : $1: 1.8$. Genital plate present. 
24

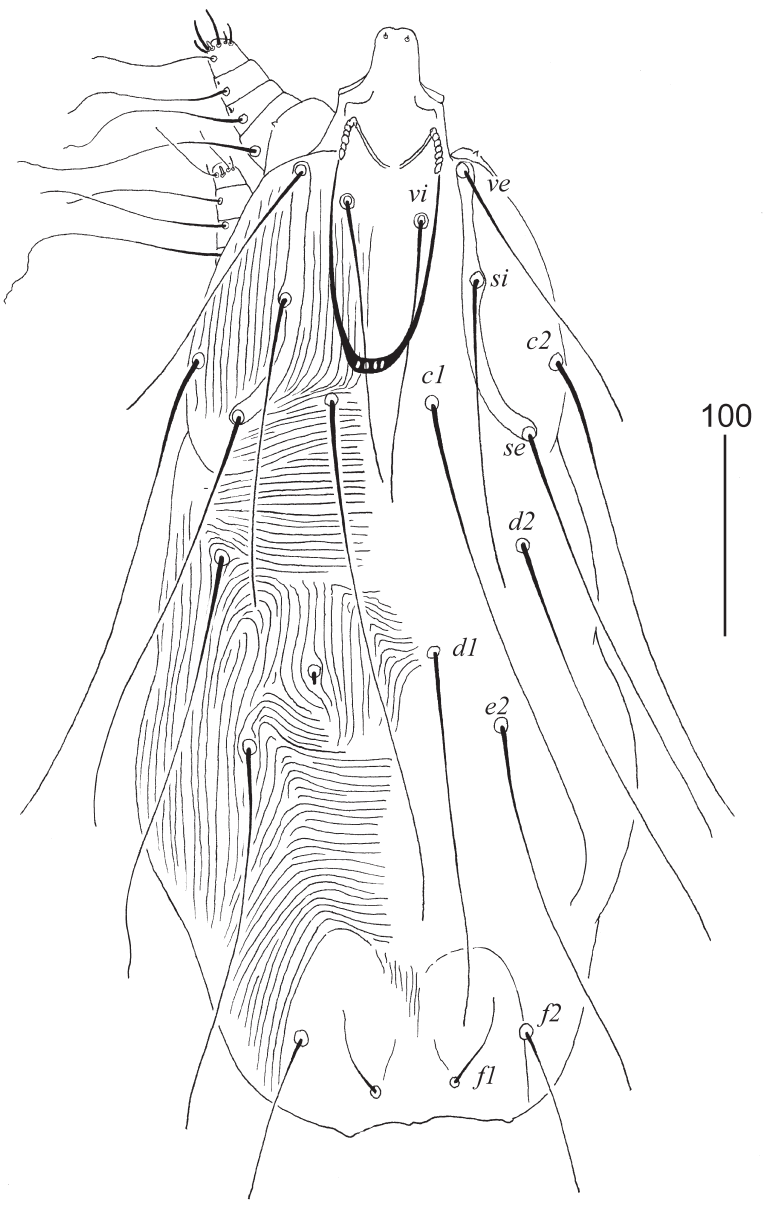

25

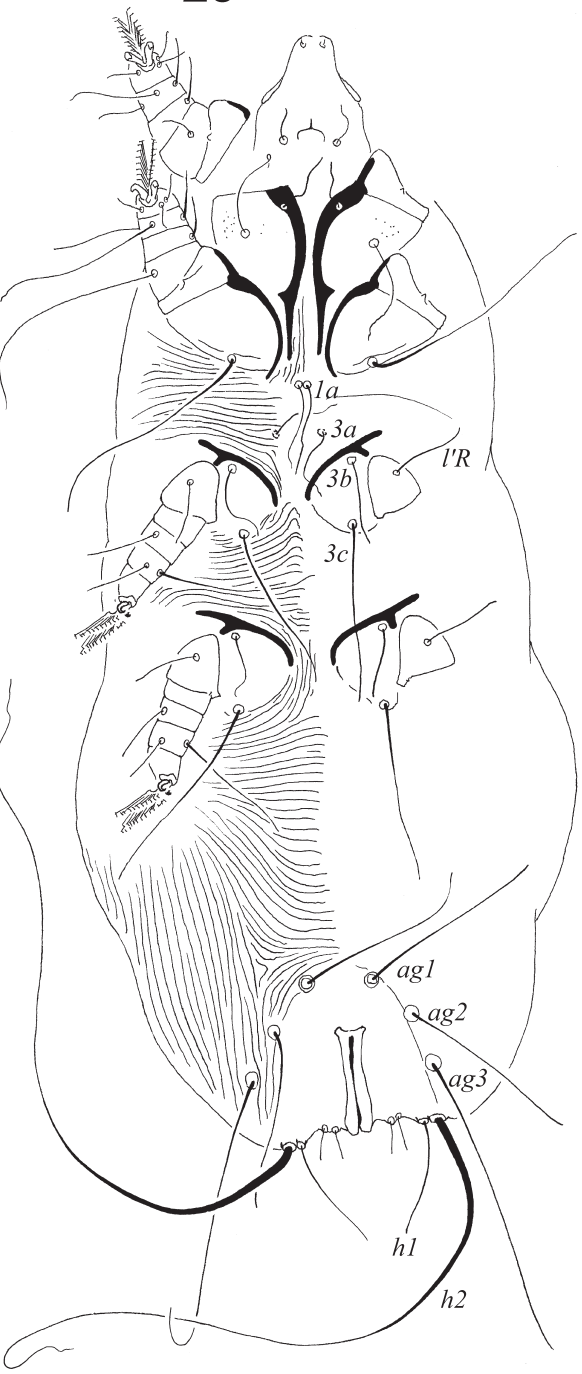

Figs. 24, 25. Pseudopicobia hapaloptila sp. n., female. 24 - dorsal view; 25 - ventral view.
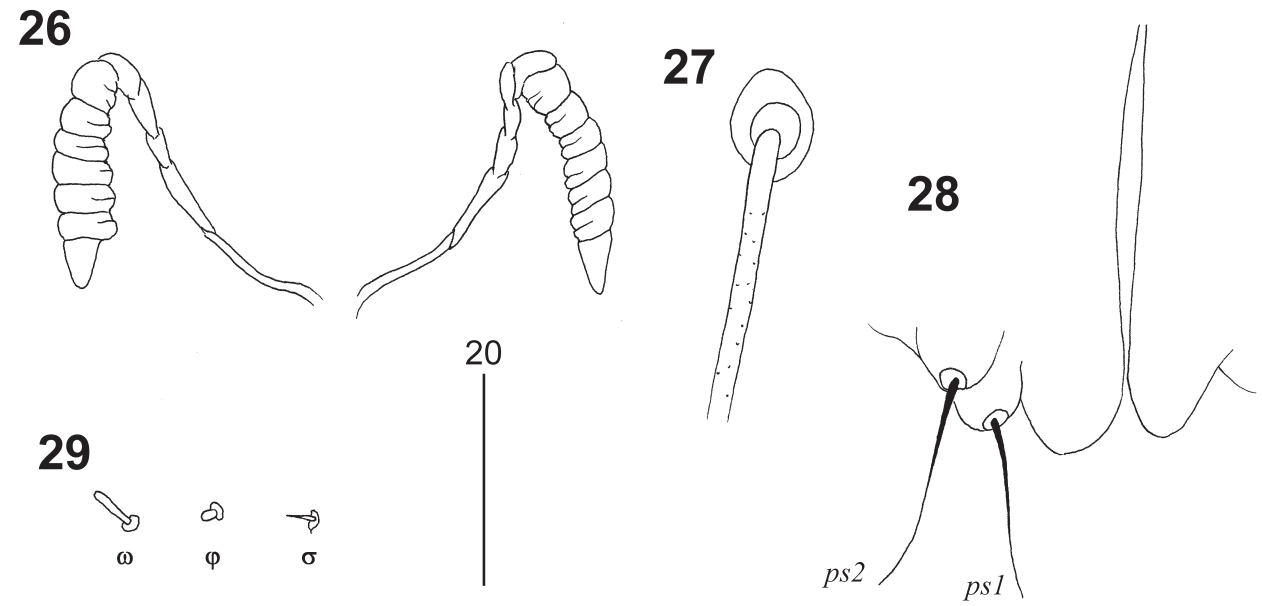

Figs. 26-29. Pseudopicobia hapaloptila sp. n., female. $\mathbf{2 6}$ - peritremes; $\mathbf{2 7}$ - propodonotal seta ve; $\mathbf{2 8}$ - genital region in ventral view; 29 - solenidia of leg I. 
Both pairs of pseudanal setae subequal in length. All coxal fields well sclerotized, I punctate, II-IV apunctate. Setae $3 c$ about twice as long as $3 b$. Legs: Antaxial and paraxial members of claws unequal in size. Setae l'RIII reach, at most, to genu. Setae $t c$ "III-IV slightly (1.2 times) longer than $t c ' I I I-I V$. Lengths of setae: vi 135 (140), ve 135 (145), si 150 (160), se 230 (220-235), c1 265 (265), c2 230 (245), d1 190 (180), d2 210 (220), e2 185 (195), fl 40 (40), f2 75 (80), h1 70 (55-65), h2 345 (350-360), ag1 105 (115), ag2 80 (95), ag3 145 (170), ps1 20 (20), ps2 20 (20), tc'III-IV (55-65), tc'”III-IV (70-80), l'RIII 45 (35-40), $3 b 40$ (45), 3c 85.

Male. Not found.

Type host: White-faced nunbird Hapaloptila castanea (Verreaux, 1866) (Piciformes: Bucconidae).

Locality: Ecuador, Riobamba ( $\left.1^{\circ} 40^{\prime} 24.45^{\prime \prime S}, 78^{\circ} 38^{\prime} 52.86^{\prime \prime W}\right)$ coll. E. Feyer. Host specimen deposited in the ZSM. Mites removed by M. Skoracki.

Site of infection: Quills of body feathers.

Type material: Female holotype and two female paratypes are deposited in the AMU (Reg. No. AMU-SYR.363).

E ty mology: The name of this new species refers to the generic name of the host - Hapaloptila.

Differential diagosis: See differential diagnosis for P. nonnula sp. $\mathrm{n}$.

\section{Key to the genus Pseudopicobia gen. n. - females}

1. Pygidial shield absent. Setae se and $c l$ situated at same transverse level .............. P. malacoptila sp. n.

- Pygidial shield present. Setae se situated posterior to level of setae $\mathrm{c} 1$......................................................... 2

2. Length ratio of setae vi : si $1: 1.2-1.4$. Setae $h 12-3.5$ times longer than $f 1$. Length ratio of setae $a g 1: a g 2$ 1.9-2 : 1. Leg setae $l$ 'RIII reach to tarsus P. nonnula sp. $\mathrm{n}$

- Length ratio of setae vi: si 1 : 1 . Setae $h 1$ 1.4-1.8 times longer than $f 1$. Length ratio of setae $a g 1: a g 2$ $1.2-1.3: 1$. Leg setae $l$ 'RIII reach, at most, to genu ... P. hapaloptila sp. $\mathrm{n}$.

Acknowledgements. We would like to thank Prof. Gerhard Haszprunar (Director of ZSM) and to the staff of the ornithological section (ZSM), Ruth Diesner and Markus Unsöld, for making available samples of dry bird skins for the present study. We also thank Dr. Richard Kraft (ZSM) for his help during our studies and Barry Nattress (Tingley, Wakefield, West Yorkshire, England) for critical review of the manuscript. This work was financially supported by the Polish Committee for Scientific Research (Grant No. NN 303802540) and by the grant founded by Bavarian Ministry of Science, Research and the Arts.

\section{REFERENCES}

Bochkov A.V., O'Connor B.M., Wauthy G. 2008: Phylogenetic position of the family Myobiidae within the Prostigmata (Acari: Acariformes). Zool. Anz. 247: 15-45.

CAsto S.D. 1977: Cuculiphilus lobatus gen. n., sp. n. representing a new subfamily of quill mites (Acarina: Syringophilidae) from the groove-billed ani, Crotophaga sulcirostris (Cuculiformes: Cuculidae). Southwest. Naturalist 22: 169-176.

Clements J.F. (Ed.) 2007: The Clements Checklist of Birds of the World. 6th Edition, Cornell University Press, Ithaca, 864 pp.

Grandjean F. 1939: Les segments postlarvaires de l'hysterosoma chez les Oribates (Acariens). Bull. Soc. Zool. (France). 64: 273-284.

Grandjean F. 1944: Observations sur les Acariens de la famille des Stigmaeidae. Archives Sci. Phys. Nat. 26: 103-131.

Johnston D.E., Kethley J.B. 1973: A numerical phenetic study of the quill mites of the family Syringophilidae (Acari). J. Parasitol. 59: 520-530.

Kethley J.B. 1971: Population regulation in quill mites (Acari: Syringophilidae). Ecology 52: 1113-1118.

Kethley J.B. 1990: Acarina: Prostigmata (Actinedida). In: D.L. Dindal (Ed.), Soil Biology Guide. Wiley and Sons, New York, pp. 667-754.
Kivganov D.A., Sharafat G.S. 1995: [Review of the family Syringophilidae (Acari) with the description of new genera and species]. Zool. Zh. 74: 82-91. (In Russian).

NATtRess B. 2011: Horizontal transmission of Syringophilopsis kirgizorum (Acari: Cheyletoidea: Syringophilidae). Acarina 19: 270 .

SkoRACKI M. 2011: Quill mites (Acari: Syringophilidae) of the Palaearctic region. Zootaxa 2840: 1-415.

Skoracki M., Bochkov A.V., O'Connor B.M. 2011: Notes on quill mites (Acariformes, Syringophilidae) from aquatic birds in North America. Acta Parasitol. 56: 325-330.

Skoracki M., Michalik J., Skotarczak B., Rymaszewska A., Sikora B., Hofman T., Wodecka B., Sawczuk M. 2006: First detection of Anaplasma phagocytophilum in quill mites (Acari: Syringophilidae) parasitizing passerine birds in Poland. Microbes \& Infection 8: 303-307.

Skoracki M., O'Connor B.M. 2010: New taxa of quill mites (Acari: Cheyletoidea: Syringophilidae). Zootaxa 2341: 1-32.

Skoracki M., Sikora B., Ozminski M. 2012: A new quill mite species (Acari: Syringophilidae) parasitising tinamous (Aves: Tinamiformes). Syst. Parasitol. 81: 109-113. 